\title{
Evaluation of Nailfold Capillaroscopy Pattern in patients with Primary Osteoarthritis of the Hands
}

Yasser A. Elmotaleb Gazar ${ }^{1}$ MD; Sherif M. Ismail ${ }^{2, *}$ MD; Ahmed M. Fahmy ${ }^{1}$ MD

\section{*Corresponding Author: \\ Yasser A. Elmotaleb Gazar \\ dr.yasser.rh@yahoo.com}

Received for publication September 11, 2021; Accepted November 22, 2021; Published online November 22,2021 .

Copyright The Authors published by Al-Azhar University, Faculty of Medicine, Cairo, Egypt. Users have the right to read, download, copy, distribute, print, search, or link to the full texts of articles under the following conditions. Creative Commons AttributionShare Alike 4.0 International Public License (CC BY-SA 4.0).

doi: 10.21608/aimj.2021.95113.1569

${ }^{1}$ Rheumatology And Rehabilitation Department,Faculty of Medicine, Al-Azhar University, Cairo , Egypt.

${ }^{2}$ Rheumatology, Physical Medicine, and Rehabilitation Department, National Research Center, Cairo, Egypt.

\begin{abstract}
Background: Hand osteoarthritis (OA) can be a distressing disorder that impairs a patients' quality of life. There is a relation between OA and vascular damage, especially atherosclerosis, and $\mathrm{OA}$ are both common chronic conditions associated with aging and obesity.

Aim of The Work: To examine nailfold microcirculation in individuals with hand OA for early detection and differentiation from other mimics.

Patients and Methods: In this cross-sectional, observational study, about 56 patients with hand OA (mean age $56.2 \pm 8$.4years) were enrolled. All subjects underwent a standard radiology X-Ray examination of the hands, and the Kellgren-Lawrence (K-L) radiographic grading scale has been applied. Nailfold vascular examination was performed.

Results: With a mean age of 56 years, $44(78.6 \%)$ of the 56 patients studied were females, and 12 were males. Kellgren and Lawrence scoring was mild (grade II) in one patient (50\%) and severe (grade IV) in one patient $(50 \%)$ in the male patients without pain, while in those with hand pain, it was moderate (grade III) in eight patients (80\%) and severe (grade IV) in two patients (20\%). Nailfold examination for studied subjects showed that there were about 41 patients (73.2\%) with low capillary density and 32 patients $(57.1 \%)$ with morphological changes. Conclusion: Our findings provided a general description of the NFC findings most likely to be seen in OA patients. Vascular anomalies may play a role in the illness progression and may assist in elucidating because the condition is frequently found in the distal digit joints.

Keywords: Osteoarthritis (OA); Nailfold capillaroscopy (NFC); Kellgren and Lawrence system $(K-L)$; Distal Interphalangeal (DIP); Proximal Interphalangeal (PIP).

Disclosure: The authors have no financial interest to declare in relation to the content of this article. The Article Processing Charge was paid for by the authors.

Authorship: All authors have a substantial contribution to the article.
\end{abstract}

INTRODUCTION

Symptomatic hand osteoarthritis $(\mathrm{OA})$ is a condition that starts in middle life and becomes more common. It is among the most debilitating joint illnesses known to humankind, impacting up to $13 \%$ of women and $10 \%$ of men ${ }^{1}$. The distal interphalangeal (DIP) and proximal interphalangeal (PIP) joints are the most impacted, preceded by the base of the thumb joint .

Bouchard's nodes at the PIP joints and Heberden's nodes at the distal interphalangeal are frequently shown through hand OA. These nodes may be tender at first but become non-tender with time ${ }^{3}$

They are valuable clinical indicators for diagnosing hand OA, particularly when combined with other disease features . ${ }^{4}$

Hand OA is typically characterized by pain during use and only slight stiffness in the morning or following a period of inactivity (4). Typically, the discomfort begins gradually and is accompanied by decreasing function of the influenced joints . ${ }^{3}$
No treatments for OA have been proven to have a disease-modifying effect; thus, prevention is important and will be optimized with a better awareness of the modifiable risk factors for OA. Vascular pathology, particularly, atherosclerosis (thinner arterial wall), and OA are two major chronic diseases associated with aging and obesity. 5

However, because some studies found a link between arterial narrowing and hand and knee $\mathrm{OA}$ incidence, the link between vascular disease and OA remained ambiguous $\cdot 6,7,8$

Capillaroscopy of the nailfold is a very sensitive, low-cost, safe, simple, and noninvasive imaging method utilized to analyze the morphology of feeding capillaries in the nailfold area ${ }^{9}$

The goal of this study was to analyze nailfold microcirculation in patients with hand $\mathrm{OA}$ and quantify and qualitatively assess morphological and structural changes, as well as discover useful characteristics that could aid in early identification and distinction from other mimics. 


\section{PATIENTS AND METHODS}

The study is a cross-sectional study in which about 56 patients were recognized with primary hand OA as per the American College of Rheumatology (10) criteria, which involve the following: (a) pain, aching, or stiffness in hand; (b) hard tissue expansion of 2/10 chosen joints in hand (chosen joints comprise the second and third DIP joints, second and third PIP joints, and second and third PIP joints),

and both hands' initial CMC joint); (c) Less than three swollen MCP joints; (d) Expansion of two or more DIP joints by hard tissue or malformation in two or more of the ten chosen joints.

The hospital's ethics committee accepted the research protocol; all participants provided informed written consent. Those 56 patients were assessed at Al Hussein University Hospital between August 2019 and January 2020. None of the patients included in this study had psoriatic arthritis, rheumatoid arthritis, gout, nor secondary OA.

Plain radiographs of the hands of the investigated individuals were taken in the posteroanterior $(\mathrm{P}-\mathrm{A})$ view, using the Kellgren-Lawrence (K-L) radiographic grading scale, which reflects the severity of OA on a scale of 0-4, with 0 indicating no OA and 4 indicating severe OA. The KellgrenLawrence scale is typically used to grade hand OA at the DIP, PIP, thumb interphalangeal, thumb metacarpal, and thumb metacarpal trapezioscaphoid joints (11-13).

Nailfold examination for study subjects was conducted using the Dino-Lite capillaroscopy Pro (MEDL4N Pro) 200x magnification and was performed by the same researcher for all patients. Any nailfold capillary abnormality found was noted, including capillary enlargement or elongations, architectural derangement, hemorrhages, capillary loss, neovascularization, or other peri-capillary findings. The following points were scored for the little and ring fingers of each hand for each subject:

\section{Architectural derangement}

Capillary density changes

Architectural dysregulation was defined as any alteration in the orientation, size, or shape of capillaries and was quantified on a scale ranging from 0 to 3 , with 0 indicating no change.

Changes in less than $33 \%$ of all capillaries were assigned 1 on the scale. If one-third to two-thirds $(33 \%-66 \%)$ of the capillaries were associated, a score of 2 was assigned, whereas participation of more than two-thirds $(66 \%)$ of the capillaries was assigned a value of 3 on the scale (14).

Additionally, changes in capillary density were assigned a score between 0 to 3 based on the degree of the capillary loss. About nine or more capillaries per millimeter were assigned a score of 0 , six to nine capillaries per millimeter were assigned a score of one, three to six capillaries per millimeter were assigned a score of two, and less than three capillaries were assigned a value of three (15).

\section{Statistical analysis}

IBM SPSS software version 22.0, IBM Corp., Chicago, IL, USA, tabulated and interpreted data.

\section{RESULTS}

Of 56 patients studied, about $44(78.6 \%)$ patients were females, and 12 were males with a mean age of 56 years (Table 1$)$.

Regarding hand pain in studied patients in both sexes, in males, hand pain was present in ten patients $(83.3 \%)$ and absent in two patients $(16.7 \%)$. In females, patient's hand pain was present in about 36 patients $(81.8 \%)$ and absent in about 8 patients (18.2\%), as shown in (Fig.1)

Regarding the Kellgren and Lawrence system, morphological changes and low capillary density results in the studied patients were divided according to sex and clinical hand pain, as shown in (Table2), as follows;

In male patients with no hand pain $(\mathrm{n}=2)$, Kellegren Lawrence class was mild (grade II) in one patient $(50 \%)$ and severe (grade IV) in one patient $(50 \%)$. There were no morphological changes, and there was low capillary density in one "severe" patient (50\%).

In male patients with hand pain $(\mathrm{n}=10)$, Kellegren Lawrence class was moderate (grade III) in eight patients (80\%), and severe (grade IV) in two patients (20\%). There were morphological changes in six "moderate" patients (60\%), and one "severe" patient $(10 \%)$. There was low capillary density in seven "moderate" patients (70\%), and one "severe" patient $(10 \%)$.

In female patients with no hand pain $(\mathrm{n}=8)$, Kellegren Lawrence class was mild (grade II) in six patients (75\%), and moderate (grade III) in two patients $(25 \%)$. There were morphological changes in three "mild" patients (37.5\%), and one "moderate" patient $(12.5 \%)$.

There was low capillary density in four "mild" patients $(50 \%)$, and one "severe" patient (12.5\%).

In female patients with hand pain $(\mathrm{n}=36)$, Kellegren Lawrence class was mild (grade II) in eight patients $(22.2 \%)$, moderate (grade III) in 21 patients $(58.3 \%)$ and severe (grade IV) in seven patients $(19.4 \%)$. There were morphological changes in four "mild" patients (11.1\%), 13 "moderate" patients $(36.1 \%)$ and four "severe" patients $(11.1 \%)$. There was low capillary density in 5 "mild" patients (13.9\%), 17 "moderate" patients $(47.2 \%)$ and 5 "severe" patients (13.9\%).

So, there were about 41 patients $(73.2 \%)$ with low capillary density in all studied patients. 
Studied patients.

$(\mathbf{N}=\mathbf{5 6})$

Age (years)

Sex

\begin{tabular}{lll} 
Mean \pm SD & $56.2 \pm 8.4$ & \\
Min - Max & $46-67$ & \\
Male & 1 & $21.4 \%$ \\
\hline Female & 2 & $78.6 \%$ \\
\end{tabular}

Table (1): description of age \& sex in all studied patients.

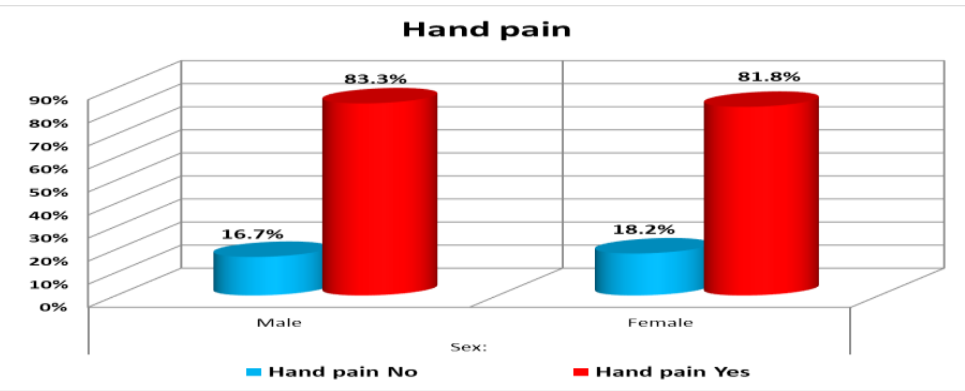

Fig. 1 : Description of hand pain in studied patients according to sex.

\begin{tabular}{|c|c|c|c|c|c|c|c|c|c|c|c|c|c|}
\hline \multirow{3}{*}{\multicolumn{2}{|c|}{$\begin{array}{c}\text { Sex } \\
\text { Hand pain }\end{array}$}} & \multicolumn{6}{|c|}{ Male $(\mathrm{N}=12)$} & \multicolumn{6}{|c|}{ Female $(N=44)$} \\
\hline & & \multicolumn{3}{|c|}{ No pain $(\mathrm{N}=2)$} & \multicolumn{3}{|c|}{ With pain $(N=10)$} & \multicolumn{3}{|c|}{ No pain $(N=8)$} & \multicolumn{3}{|c|}{ With pain $(N=36)$} \\
\hline & & $\mathbf{n}$ & $\begin{array}{l}\text { Morph. } \\
\text { changes }\end{array}$ & $\begin{array}{c}\text { Low Cap. } \\
\text { den sity }\end{array}$ & $\mathbf{N}$ & $\begin{array}{l}\text { Morph. } \\
\text { changes }\end{array}$ & $\begin{array}{c}\text { Low Cap. } \\
\text { den sity }\end{array}$ & $\mathbf{N}$ & $\begin{array}{l}\text { Morph. } \\
\text { changes }\end{array}$ & $\begin{array}{c}\text { Low Cap. } \\
\text { density }\end{array}$ & $\mathbf{N}$ & $\begin{array}{l}\text { Morph. } \\
\text { ch anges }\end{array}$ & $\begin{array}{l}\text { Low Cap. } \\
\text { density }\end{array}$ \\
\hline \multirow{3}{*}{ 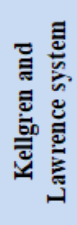 } & Mild & $\begin{array}{c}1 \\
50 \%\end{array}$ & $\begin{array}{c}0 \\
0 \%\end{array}$ & $\begin{array}{c}0 \\
0 \%\end{array}$ & $\begin{array}{c}0 \\
0 \%\end{array}$ & $\begin{array}{c}0 \\
0 \%\end{array}$ & $\begin{array}{c}0 \\
0 \%\end{array}$ & $\begin{array}{c}6 \\
75 \% \\
\end{array}$ & $\begin{array}{c}3 \\
37.5 \%\end{array}$ & $\begin{array}{c}4 \\
50 \%\end{array}$ & $\begin{array}{c}8 \\
22.2 \%\end{array}$ & $\begin{array}{c}4 \\
11.1 \%\end{array}$ & $\begin{array}{c}5 \\
13.9 \%\end{array}$ \\
\hline & Mod erate & $\begin{array}{c}0 \\
0 \%\end{array}$ & $\begin{array}{c}0 \\
0 \%\end{array}$ & $\begin{array}{c}0 \\
0 \%\end{array}$ & $\begin{array}{c}8 \\
80 \%\end{array}$ & $\begin{array}{c}6 \\
60 \%\end{array}$ & $\begin{array}{c}7 \\
70 \%\end{array}$ & $\begin{array}{c}2 \\
25 \%\end{array}$ & $\begin{array}{c}1 \\
12.5 \%\end{array}$ & $\begin{array}{c}1 \\
12.5 \%\end{array}$ & $\begin{array}{c}21 \\
58.3 \%\end{array}$ & $\begin{array}{c}13 \\
36.1 \%\end{array}$ & $\begin{array}{c}17 \\
47.2 \%\end{array}$ \\
\hline & Severe & $\begin{array}{c}1 \\
50 \%\end{array}$ & $\begin{array}{c}0 \\
0 \%\end{array}$ & $\begin{array}{c}1 \\
50 \%\end{array}$ & $\begin{array}{c}2 \\
20 \%\end{array}$ & $\begin{array}{c}1 \\
10 \%\end{array}$ & $\begin{array}{c}1 \\
10 \%\end{array}$ & $\begin{array}{c}0 \\
0 \%\end{array}$ & $\begin{array}{c}0 \\
0 \%\end{array}$ & $\begin{array}{c}0 \\
0 \%\end{array}$ & $\begin{array}{c}7 \\
19.4 \%\end{array}$ & $\begin{array}{c}4 \\
11.1 \%\end{array}$ & $\begin{array}{c}5 \\
13.9 \%\end{array}$ \\
\hline
\end{tabular}

Table 2: Description of Kellgren and Lawrence (K-L), morphological changes \& low capillary density in studied patients according to sex and clinical hand pain.

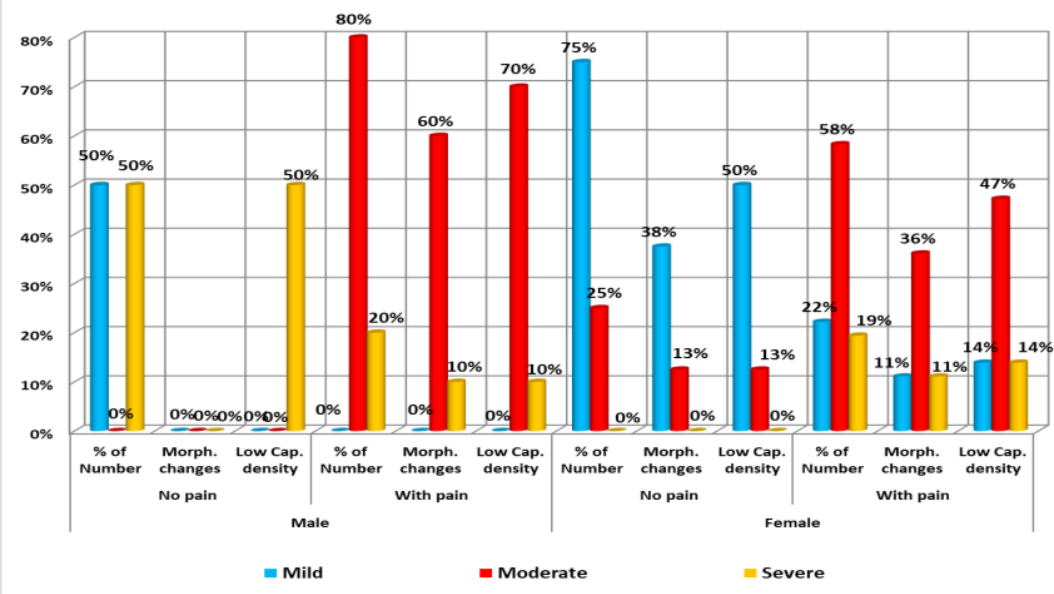

Fig 2: Kellgren and Lawrence (K-L) description, morphological alterations, and low capillary density in the studied individuals according to sex and clinical hand pain. 


\section{DISCUSSION}

Osteoarthritis (OA) is a significant burden on both individuals and society. Although difficult to describe, it is defined by discomfort associated with the use and structural abnormalities of all synovial joint tissues, including ligaments, cartilage, subchondral bone, synovium, and capsule ${ }^{16}$

The relationship between OA and vascular damage has been recognized and researched previously. Surely, the vascular model cannot account for all clinical symptoms in OA, including osteophyte production, although this and some other traits are likely secondary responses to joint mechanical changes. According to Conaghan and colleagues, $\mathrm{OA}$, or at least its structural evolution, maybe largely an atheromatous vascular disease of subchondral bone.${ }^{16}$ In a recent systemic review published in 2020, proof from several studies suggested a positive association between the severity of vascular pathology and the likelihood of having hand or knee OA. The results of this systematic review support the hypothesis that vascular pathology may be involved in OA initiation and progression with consistent evidence for an association of vascular pathology with hand and knee OA.${ }^{17}$ Pathological changes in blood vessels (vascular pathology), particularly atherosclerosis or thickening of the arterial wall, and $\mathrm{OA}$ are common chronic conditions associated with aging and obesity. ${ }^{5}$ Our study was carried out on a total of 56 patients (mean age of all studied patients was $56.2 \pm 8.4$ years), 12 males $(21.4 \%)$ and 44 females $(78.6 \%)$. In both male and female groups, the hand pain group was significantly higher in number than those who reported no hand pain at the time of assessment, and the figures were statistically similar between the male and female groups. The male "no pain" group had just two patients, and the low capillary density was found in the patient with severe X-ray severity classification. In the male group with pain, the highest morphological abnormalities and lower capillary density were found in the moderate X-ray severity classification. While in the females, the highest of both were found in the mild X-ray severity classification in the "No pain" group, and similar to the males in the "Pain" group. One of the earliest and most well-known works on Osteoarthritic capillaroscopic findings was that of Conners and McGrath . ${ }^{18}$

We contrasted the nailfold capillaries of 28 patients with distal interphalangeal joint OA to those of 23 age- and sex-matched controls without OA. Individuals with $\mathrm{OA}$ had a considerably decreased capillary density in their nail folds and substantially more capillary morphological anomalies, such as bleeding, 'drop out,' irregularity, and dilatation. Although we detected no hemorrhages or dropouts in our OA patients, the rest of their observations certainly agreed with our findings (Figure 3 A, B). We did not compare to normal controls in our study as we were more focused on describing the visible abnormalities found in the known pathologic group.

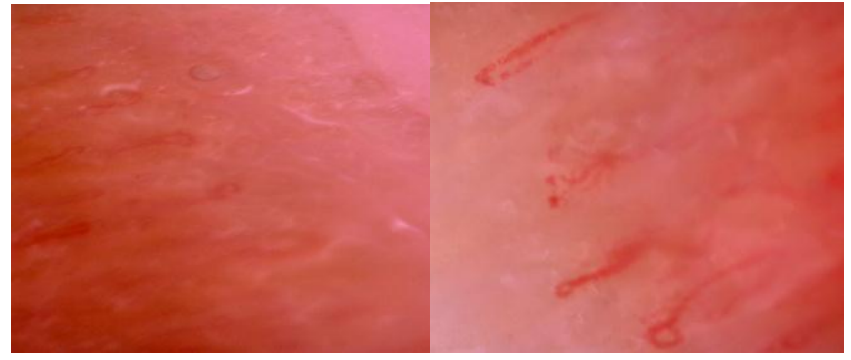

A

B

Fig. 3: from the study group shows: (A) irregular Nailfold Capillary shapes in the distal row, in form of tourtiosities, crossings, apical dilatations, serpentine shapes.

(B) irregular Nailfold Capillary shapes and disorganization in the distal row, in form of tourtiosities, multiple branching (bushy), crossings, elongations, serpentine shapes. Extravasation is also noted.

Their assessment included the measurement of digital artery pressure using a doppler flowmeter. The pressure was determined in the finger in both the baseline and heated states, and the ratio of the finger pressure to the systolic brachial artery pressure was calculated. The results are given as a person's average digital to systemic blood pressure ratio per digit.

In their findings, It was discovered that individuals associated with $\mathrm{OA}$ had warmer fingertips and lowered finger to brachial blood pressure ratios. Additionally, they discovered strong relationships between the number of capillaries in the nailfold and the average joint discomfort, as well as between capillary morphological alterations and joint swelling. This agrees with our finding about clear higher morphological anomalies in the male pain group than the non-pain group. These findings establish a link between interphalangeal joint OA and capillary anomalies and density in the Nailfold. The decreased capillary density in that location naturally results in decreased blood perfusion (shown in $73.2 \%$ of our OA patients).

Vascular anomalies may play a role in the process and may explain why the condition is frequently found in the distal digit joints. Over a century ago, an ischemia process related to OA structural disease was proposed ${ }^{19}$ Surprisingly, a minor investigation of this possibility was reported, although NFC has been an easily available and widespread tool to rheumatologists now for many years. The observed defects may represent irregularities in the vascular supply of the synovium or juxta-articular bone in the underlying DIP joints, which may result in decreased oxygenation or nutritional intake, as well as vulnerability to reperfusion or immunological insult. On the other hand, vascular abnormalities may occur due to DIP joint disruption caused by OA and play no role in the pathophysiology of joint anomalies.

Patients were checked once, at least three days after discontinuing anti-inflammatory treatment. This was also done in our study; we were careful not to 
examine patients who have had physiotherapy sessions on their hands 24 hours before the NFC assessment.

Since both Conners and McGrath's and our studies are cross-sectional, the data cannot establish a causal association between these vascular anomalies and the onset or progression of OA.

Another interesting and more recent study was carried out by Fioverenti and colleagues ${ }^{20}$, who compared the capillaroscopic microvascular patterns in 56 patients with Erosive OA, 46 patients with Nodal OA, and 50 normal controls. The general classification was different from ours as well as the aim of assessment; they described that NFC in erosive OA was similar in findings described for psoriatic arthritis. One of their interesting findings that we did not encounter in our study group was detecting many capillary enlargements in the erosive OA group (about 40\%). They also found a statistically significant difference between OA patients and controls regarding tortuous loops, which was one of our prominent morphological abnormalities in our OA patients. They did not assess capillary density. Morphological changes were found in almost all our OA subgroups, with varying degrees in different X-ray severity classes. The total morphological changes were found in 32 out of 56 patients $(57 \%)$.

This is somewhat like Fioverenti's findings; they found regular-shaped capillaries in 53 percent of the erosive and 46 percent of the nodal group. So, about half of their total studied OA patients had morphological pathologies. They did find microhemorrhages in 11 out of their 23 OA patients; while we found no evident signs of microhemorrhages in our group, but we were keen to exclude any patient with recent hand trauma, autoimmune disease, peripheral vascular disease, or any other external possible cause of capillary hemorrhages from the beginning. Notable to say is that their OA age group was higher than ours, $60.5+$ 6.6 for erosive and $60.2+-7.0$ for nodal, while (Ours was $56.2 \pm 8.4$ ). The male to female ratio in their study group was relatively like ours. Our study found low capillary density in most of the indeed studied OA group of patients $(73.2 \%)$, but it was a mild affection (7-9 capillaries per mm), (Figure (4), A, B).

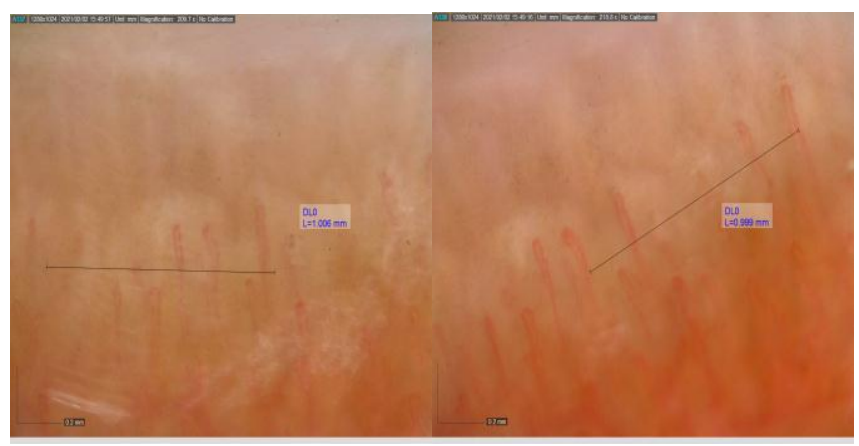

Fig. 4: A and B: Figures from the study group showing areas of low Nailfold Capillary density per linear $\mathrm{mm}$. (8 capillaries in figure A, 6 capillaries in figure B)
Penin and colleagues worked on NFC in osteoarthritis and SSC patients, and they also found mildly reduced capillary density in OA. Additionally, there were statistically significant variations in the degree of density loss in individuals with systemic sclerosis compared to those with $\mathrm{OA}$ and other rheumatic diseases. ${ }^{21}$

\section{CONCLUSION}

Our findings gave a general description of the NFC findings most likely to be encountered in OA patients; most of our patients were female, and, in both males and females, those with hand pain were significantly more than those without hand pain. No great NFC differences were found between male and female groups or between different severities of .radiographic findings

More research is needed on OA pathology and association with vascular abnormalities, and how utilization of NFC can be more helpful in diagnosis and follow-up of OA or help differentiate it from other rheumatic diseases affecting small joints of the .hands, especially the DIP The limitations of our study were mainly the low number of patients and were performed as a singlecenter study. Indeed, a larger and more widespread cohort would have yielded more reliable results. The disease duration was not considered in our work, despite being a significant decisive factor on many variables in OA. Also, more clinical, and not just radiographic grouping and correlations were needed to help better understand the NFC changes observed in this group of patients.

\section{REFERENCES}

1. Zhang $\mathrm{Y}$ and Jordan JM. Epidemiology of osteoarthritis. Clin Geriatr Med. 2010; 26: 355-369.

2. Zhang Y, Niu J, Kelly-Hayes M, etal. Prevalence of symptomatic hand osteoarthritis and its impact on functional status among the elderly: The Framingham Study. Am J Epidemiol .2002; 156:1021-7.

3. Glass GG. Osteoarthritis. Dis Mon 2006; 52:343-62.

4. Zhang W, Doherty M, Leeb BF, et al. EULAR evidence-based recommendations for the diagnosis of hand osteoarthritis: report of a task force of ESCISIT. Ann Rheum Dis . 2009; 68:8-17.

5. Felson DT, Lawrence RC, Dieppe PA, et al. Osteoarthritis: new insights. Part 1: the disease and its risk factors. Ann Intern Med .2000; 133:635-46.

6. Hoeven TA, Kavousi M, Clockaerts S, et al. Association of atherosclerosis with presence and progression of osteoarthritis: the Rotterdam Study. Ann Rheum Dis . 2013; 72:646-51.

7. Jonsson H, Helgadottir GP, Aspelund T, et al. Hand osteoarthritis in older women is associated with carotid and coronary atherosclerosis: the AGES Reykjavik study. Ann Rheum Dis. 2009; 68:1696700.

8. Wang Y, Novera D, Wluka AE, et al. Association between popliteal artery wall thickness and knee structure in adults without clinical disease of the 
knee: a prospective cohort study. Arthritis Rheumatol. 2015; 67:414-22.

9. S. N. Lambova and U. Muller-Ladner, "Capillaroscopic pattern '. in systemic lupus erythematosus and undifferentiated connective tissue disease: what we still have to learn?" Rheumatology International, vol. 33, no. 3, 2013 pp; 689-695.

10. Altman R, G Alarcón, D Appelrouth, et al. The American College of Rheumatology criteria for the classification and reporting of osteoarthritis of the hand. Arthritis Rheum. 1990; 33: 1601-1610.

11. ellgren JH, Lawrence JS. Radiological assessment of osteo-arthrosis. Ann Rheum Dis. 1957; 16:494-502. doi: 10.1136/ard.16.4.494

12. Zhang $\mathrm{Y}$ and Jordan JM. Epidemiology of osteoarthritis. Rheum Dis Clin North Am. 2008; 34: 515-529.

13. Bijsterbosch J , I K Haugen, C Malines, et al. Reliability, sensitivity to change and feasibility of three radiographic scoring methods for hand osteoarthritis. Ann Rheum Dis. 2011; 70: 1465- 1467.

14. Gayraud, M., Raynaud's phenomenon. Joint Bone Spine, 2007; 74(1): p. e1-e8.

15. Sulli A., M E Secchi, C Pizzorni, et al., Scoring the nailfold microvascular changes during the capillaroscopic analysis in systemic sclerosis patients. Annals of the rheumatic diseases. 2008; 67(6): p. 885-887.
16. Conaghan PG, Vanharanta $\mathrm{H}$ and Dieppe PA. Is progressive osteoarthritis an atheromatous vascular disease? Annals of the Rheumatic Diseases. 2005; 64:1539-1541.

17. Sultana M., Chloe Dawson, Yuanyuan Wang, et al, Vascular Pathology and Osteoarthritis: A Systematic Review. The Journal of Rheumatology .May 2020; 47 (5) 748-760.

18. R. O. DAY, T. WACHER, D. CAIRNS, et al, NAILFOLD CAPILLARY CIRCULATION IN OSTEOARTHRITIS Rheumatology, Volume 32, Issue 12, December 1993; Pages 1062-1065.

19. Wollenberg GA. Die Ätiologie der Arthritis deformans im Lichte des Experimentes. Archiv Orthopädie, Mechanotherapie Unfallchirurgie . 1909;7:226-42.

20. A Fioravanti, C Tofi, A Cerase, et al, Capillaroscopic findings in erosive and nodal osteoarthritis of the hands, Clin Rheumatol,.2001;20(3):174-6.

21. Penin I.N., Maslyanskiy A.L., Konradi A.O., et al, Possibilities of nailfold capillaroscopy in the differential diagnosis of immuno-inflammatory and rheumatological diseases // HERALD of NorthWestern State Medical University named after I.I. Mechnikov. 2020; - Vol. 12. - N. 3. - P. 21-26. 